SISOMOS AMERICANOS

Revista de Estudios

Transfronterizos
Volumen XXI, número I, enero-junio de 2021

Recibido: 23 de junio de 2020

Aprobado: 26 de enero de 2021

\title{
Hukou, registro de hogares en China: desafíos de la migración interna (1958-2018)
}

\section{Hukou, register of households in China: challenges of internal migration}

\author{
(1958-2018) \\ Carmen Norambuena Carrasco* \\ Byron Duhalde Valenzuela ${ }^{* *}$ \\ Universidad de Santiago de Chile, Chile.
}

\begin{abstract}
Resumen
La migración interna en China se constituyó en un problema demográfico en los inicios de la República Popular, debido a la desigualdad entre los pobladores de las áreas rurales respecto de las urbanas. Para ejercer un control más efectivo, el gobierno aplicó en 1958 el sistema hukou, que ligó a las personas con su lugar de nacimiento, profundizando las desigualdades entre ambas zonas. A 60 años de su implementación, este sistema ha pasado por diversas reformas, aunque su propósito continúa siendo el mismo. En pleno siglo XXI, el objetivo es controlar la migración del campo a la ciudad para no sobrepoblar las megaciudades, manteniendo el equilibrio entre la migración interna y el crecimiento económico. En el presente trabajo, a través de una mirada

\footnotetext{
* Doctora en Filosofía y Letras, mención Historia de América. Universidad Complutense de Madrid, Profesora emérita, Departamento de Historia, Facultad de Humanidades, Universidad de Santiago de Chile, Investigadora del Centro de Estudios Migratorios, Universidad de Santiago de Chile. Correo electrónico: carmen.norambuena@ usach.cl ORCID: https://orcid.org/0000-0002-9259-2992

${ }^{* *}$ Licenciado en Estudios Internacionales, Universidad de Santiago de Chile. Investigador del Centro de Estudios Migratorios (FAHU-USACH), Profesor ayudante del Departamento de Estudios Políticos, Facultad de Humanidades, Universidad de Santiago de Chile. Candidato a magíster en Estudios Internacionales, IDEA-USACH. Becario del Magíster Nacional ANID-PFCHA (2020). Correo electrónico: byron.duhalde@usach.cl ORCID: https://orcid.org/0000-0003-0235-8623
} 
histórica a la institucionalidad y de una revisión de documentación oficial y de prensa nacional, se reflexiona acerca de que, pese las transformaciones sociales y económicas de China y las reformas a su sistema en la última década, este persiste en la limitación institucionalizada de los movimientos migratorios internos en el país.

Palabras clave: migración interna, China, hukou.

\begin{abstract}
Internal migration in China became a demographic problem in the early days of the People's Republic due to the inequality between rural and urban populations. To exercise more effective control, the government introduced the hukou system in 1958, which linked people to their place of birth, thus deepening the inequalities between the two areas. Sixty years after its implementation, this system has undergone various reforms, although its purpose remains the same. In the 21 st century, the programme's objective is to control migration from the rural sector to the city so as not to overpopulate the country's megacities, maintaining the balance between internal migration and economic growth. This article offers a historical examination of institutional characteristics and a review of official documentation and the domestic press. The authors reflect on how this approach continues the institutionalised limitation of internal migration movements in the country, despite the social and economic transformations of China, and reforms to the system in the last decade.
\end{abstract}

Keywords: internal migration, China, hukou.

\title{
Preámbulo
}

Los procesos migratorios contemporáneos se han posicionado en las temáticas de la historia y las ciencias sociales. Asimismo, los flujos migratorios entre países han cambiado en forma y dirección, a la vez que los conflictos armados, políticos, civiles y ambientales han impulsado la movilización de personas fuera de su país de origen. En cifras, ya en 2017 el número de migrantes internacionales bordeó los 244 millones de personas, y los migrantes internos, a nivel mundial, alcanzaron la cantidad de 740 millones de personas, triplicando a los primeros. De este último guarismo, los migrantes internos chinos alcanzan a cerca de 500 millones, ${ }^{1}$ es decir, el doble de la cantidad de migrantes internacionales (Chung, 2017). No obstante, en el ámbito de los movimientos de población, las migraciones internacionales han predominado en la agenda de los estudios migratorios. En este contexto, el presente artículo refiere a la migración rural-

\footnotetext{
${ }^{1}$ Al observar el Nuevo Plan para la Urbanización (2014) del Gobierno de la República Popular China, el porcentaje de aumento de la población urbana frente a la rural, da cuenta de tal cantidad de desplazamientos internos.
} 
urbana más cuantiosa de la historia, que corresponde al proceso migratorio interno en la República Popular China.

Efectivamente, el número de migrantes rurales en áreas urbanas de China duplica el número de migrantes internacionales. A diferencia de estos, los migrantes chinos poseen la ventaja de estar dentro de su propio país; no obstante, están en desventaja respecto a los ciudadanos urbanos a causa del sistema hukou, ${ }^{2}$ el cual vincula a la población con su lugar de nacimiento.

Este proceso ha sido abordado desde distintas perspectivas: análisis macrocausales, según las cuales se demuestra cómo las zonas que se desarrollaron económicamente por la apertura comercial han sido polos de atracción de mano de obra rural irregular (Davin, 1998); las oportunidades económicas para los migrantes rurales en las zonas de desarrollo (Fan, 1997 y el excedente de trabajo que ha permitido la precarización laboral de los migrantes rurales ( $\mathrm{Li}, 1996)$.

Es posible señalar que este proceso de migración interna posee múltiples aristas y puntos de vista desde donde aproximarse; no obstante, hay un elemento central que es constante en la mayoría de los trabajos como elemento de análisis: el sistema hukou, considerado el factor más importante de la creciente movilidad poblacional interna en China (Shen, 2013).

Después de las reformas de la última década y de la manifiesta voluntad del gobierno de la República Popular China en luchar contra la desigualdad que el sistema produce, este artículo, fruto de la revisión de información proveniente de documentos oficiales, revisión de prensa y artículos académicos, da cuenta en perspectiva histórica del desarrollo del registro de hogares al identificar las principales dificultades de los migrantes rurales en las ciudades de la China actual, las que surgen de las particularidades del proceso migratorio interno del país, enraizado en el sistema hukou (Chan y Zhang, 1999). Así entonces, se postula que pese a las reformas de la última década, que han expresado de manera directa la incorporación de migrantes rurales en las ciudades, las restricciones en su incorporación son elementos que persisten y dan cuenta de la manera en la que el sistema hukou sigue siendo la limitación institucionalizada de los flujos migratorios internos del país.

El texto consta de cuatro apartados. En el primero, se establece la posición teórica desde donde se observa el problema; luego, en el segundo se desarrolla un recorrido por la instauración del sistema hukou y los principales desafíos que enfrentaron los gobiernos de Mao Tse-Tung y Deng Xiaoping, con base en el proyecto económico que desarrolló China para posicionarse rápidamente como una de las economías más dinámicas a nivel global. En el tercer apartado, se revisan las reformas más relevantes desde el gobierno de Jiang Zemin (1993-2003) hasta la época de Hu Jintao (2003-2013) para, finalmente, en el cuarto apartado, analizar el Nuevo Plan para la Urbanización del periodo de Xi

\footnotetext{
${ }^{2}$ El término hukou se traduce textualmente como "registro familiar", lo que lo asocia a la condición hereditaria del registro.
} 
Jinping y las dificultades que se han debido enfrentar en torno al proceso de inserción de los migrantes rurales en las ciudades.

\section{Migración interna desde una perspectiva institucional}

La relevancia de los temas migratorios en las últimas décadas ha sido puesta en relieve por diversos estudios e investigaciones (Castles, Miller y Quiroz, 2004; Durand y Massey, 2003; Martínez, 2011). Con la consolidación de un proceso de globalización a escala planetaria, la migración internacional se ha posicionado como tema de interés en las agendas públicas gubernamentales (Castles, 2002; Solimano, 2008). Por otra parte, las migraciones internas son procesos que se diferencian de sus homólogas internacionales al desarrollarse dentro del territorio de un país o estado (Greenwood, 1997); movimientos que durante el último siglo han proliferado en gran parte dado el crecimiento de las economías de los países en desarrollo.

Desde un comienzo que los estudios de las migraciones con pretensión científica (Ravenstein, 1885), los enfoques más esgrimidos para explicar y abordar los procesos, provienen de la economía (Cornelius y Rosenblum, 2004), con análisis macroeconómicos y microeconómicos, teoría neoclásica de las migraciones, nueva economía de las migraciones y redes migratorias (Abad, 2003; Arango 2003). Asimismo, otras disciplinas como la historia, la antropología y la sociología han contribuido al desarrollo conceptual de los procesos migratorios. Pese a incorporarse tardíamente, la ciencia política también ha demostrado interés por estos procesos (Moyano, 2010). Sin embargo, existe un consenso en la difícil conformación hasta el momento de un modelo teórico unificado sobre las migraciones, que permita explicar y abordar su total complejidad (Arango, 2003; Durand y Massey, 2003; Zapata-Barrero, 2002).

El tardío estudio de las migraciones, por parte de la ciencia política, da cuenta de la ausencia de marcos de análisis politológicos que permitan comprender estos procesos desde las dimensiones que aborda la disciplina (Hollifield y Wong, 2000). Este estudio pretende aportar, entonces, a la reflexión politológica mediante el abordaje de un proceso migratorio interno encausado por una institucionalidad (entendida en los términos de North [1990] como un conjunto de normas que regula el comportamiento de los individuos) que, además de regular los flujos internos, es un factor incidente en la desigualdad de la China contemporánea.

En los procesos de migración interna, en que los elementos que constituyen la motivación de realizar el desplazamiento pueden ser similares a la de la migración internacional -en relación a sus determinantes (Greenwood, 1997)-, las consecuencias para el inmigrante en sí mismo son distintas; esto se debe principalmente al entorno social, cultural, político, institucional y económico al que se enfrentan al momento de arribar a destino. 
En este sentido, una diferencia entre los movimientos internacionales y los internos es que en términos político-institucionales estos poseen un menor impacto en sus consecuencias para el inmigrante, al desarrollarse dentro del mismo país, donde el Estado y sus instituciones rigen de forma homogénea en todo el territorio. Esto se ha traducido en que las investigaciones orientadas a las consecuencias de la migración para las personas tengan mayor incidencia en los beneficios económicos (Greenwood, 1997). La migración campo-ciudad se ha abordado desde sus dinámicas como procesos sociales y económicos, producto de la búsqueda de mejoras salariales y laborales por parte de las personas, bajo el título "causa de las migraciones". Aquí se inscriben y discuten verbalizaciones de los migrantes sobre razones que los habrían llevado a migrar (Singer, 1973).

Este artículo aborda un proceso de migración interna a través del estudio de un sistema que ha sido utilizado para el control de los flujos migratorios internos en China. Si bien trabajos como el de Wang (2005, septiembre) y Young (2013) ahondan en el sistema hukou desde una perspectiva histórico institucional, el presente escrito da cuenta de las consecuencias que tiene este sistema como política migratoria interna, aproximándose a lo que en términos de Mármora y Calcagno (2002) es posible señalar como política migratoria explícita. En esta perspectiva, el sistema hukou es una política migratoria interna formal que ha institucionalizado mecanismos mediante los cuales las personas pueden asentarse en otras ciudades distintas a la de su nacimiento. A través de requisitos como empleo estable, recursos financieros, estudios universitarios, entre otros requerimientos. Las personas que no poseen dichos atributos y emigran de manera informal, son despojadas de todas sus garantías sociales, tales como el derecho a salud, educación, vivienda y contrato de trabajo. Estas, al no ser sujetos de derecho a través de los mecanismos empleados por el sistema, pasan a convertirse en extranjeras en su propio país (Correa y Núñez, 2013; Chan y Buckingham, 2008; Fuentes, 2012).

\section{La República Popular China y el surgimiento del hukou}

En los albores de la República Popular, el Ministerio de Seguridad Pública diseñó el plan para el establecimiento del sistema hukou, ${ }^{3}$ al formular una serie de reglamentaciones con las características del sistema actual. ${ }^{4}$ Este comenzó en áreas urbanas y fue expandido sistemáticamente hacia las zonas rurales. En 1951, la promulgación del Reglamento Provisional sobre la Gestión del hukou en las ciudades inició la administración del registro de población permanente en zonas urbanas.

\footnotetext{
${ }^{3}$ El sistema hukou devino del sistema baojia, el cual no se aborda en el presente trabajo, pues responde a la estructura imperial de la China premoderna, donde si bien es posible encontrar elementos de continuidad, este artículo entiende el proceso de desarrollo del sistema hukou en un contexto local e internacional con características muy distintas a las del pasado.

${ }^{4}$ Restricción de la migración a zonas urbanas a través de la privación de acceso a servicios públicos como salud, vivienda y educación.
} 
En 1953 se reguló la adquisición de productos alimenticios en las ciudades, donde solo las personas con domicilio registrado podían acceder a dicha compra, medida que tenía como propósito presionar a los migrantes para que volvieran a sus lugares de origen. Posteriormente, junto al anuncio de la creación de la Oficina Nacional de Estadística, se estableció el sistema de registro hukou rural en todo el país (Young, 2013). En 1955, el gobierno expandió el régimen de las tarjetas de racionamiento de alimentos a nivel nacional, otorgándole la dirección total del sistema hukou al Ministerio de Seguridad Pública, organismo que coordinó las condiciones y limitaciones de la transferencia de personas migrantes a las ciudades.

Entre 1955 y 1957 se implementó un conjunto de medidas relacionadas con la contención de la migración rural y la contratación de trabajadores rurales en zonas urbanas (Chan y Zhang, 1999), iniciándose así una transformación hacia una política nacional del sistema hukou. Política que, en enero de 1958, fue dada a conocer por la Asamblea Popular Nacional (APN) mediante un documento conocido como Reglamento de la República Popular China sobre el Registro de Hogares (1958).

Esta normativa incorporó las clasificaciones agrícola (nongcun) y no agrícola (feinong), rural y urbano, que categorizaron a la población a partir de su lugar de nacimiento. También se creó la clasificación local y no local, que determinaba si las personas podían o no recibir los beneficios sociales, incluido el acceso a empleo en empresas estatales. ${ }^{5}$ Esto buscó producir una dependencia de las personas a su lugar de nacimiento, con el fin de desincentivar la migración. De esta forma, el sistema hukou se estructuró y clasificó a las personas de la siguiente forma:

\section{Cuadro $\mathrm{N}^{\circ}$ 1: Tipos de hukou}

\begin{tabular}{lcc}
\hline & Columna A: & Columna B: \\
& Registro hukou local & Registro hukou no local \\
\hline hukou urbano & $\begin{array}{c}\text { a) Urbano - local (citadinos } \\
\text { en su ciudad) }\end{array}$ & $\begin{array}{c}\text { b) Urbano - no local (personas } \\
\text { de ciudades en otras ciudades o } \\
\text { zonas rurales) }\end{array}$ \\
\hline hukou rural & c) Rural - local (campesinos & $\begin{array}{c}\text { d) Rural - no local (personas } \\
\text { del campo en ciudad, u otra } \\
\text { zona rural) }\end{array}$ \\
\hline
\end{tabular}

Fuente: elaboración propia.

\footnotetext{
${ }^{5}$ Las clasificaciones local y no local habilitaron a las personas para acceder a los beneficios sociales del Estado; no obstante, dependía de la clasificación agrícola y no agrícola el tipo de beneficios sociales a percibir, ya que debido a que las personas en el campo tenían medios de producción con los cuales podían sustentar sus necesidades básicas, las personas en las ciudades requerían de un apoyo mayor por parte del Estado, debido a que los esfuerzos para la industrialización estaban centrados ahí, por tanto el grueso de beneficios sociales se encontraban focalizados en las ciudades (Correa y Núñez, 2013).
} 
El Cuadro $\mathrm{N}^{\circ} 1$ muestra los tipos de registro hukou: la columna A refiere a las personas que se encuentran en el lugar de residencia acorde a su registro; la columna B refiere a las personas que se encuentran en el lugar de residencia que no es acorde a su registro. La clasificación de la letra “d)" corresponde a la población rural migrante (personas de zonas rurales que migran a zonas urbanas).

Tal reglamento restringió el principio de libre movilidad dentro del territorio nacional, pues los ciudadanos debían declarar ante las oficinas de policía local cuando sus estancias fuera de la zona de residencia superaran los tres días; también si residían de forma temporal en otras ciudades, con un plazo máximo permitido de tres meses, con solicitudes de extensión de tiempo; en caso contrario, estos debían ser devueltos a sus lugares de origen (Reglamento de la República Popular China sobre el Registro de Hogares, 1958).

Antagónicamente, la esencia restrictiva de este reglamento no se encontraba en concordancia con la Constitución Política de 1954, documento que declaraba en su artículo 90: "Los ciudadanos de la República Popular de China disfrutan de libertad de residencia y libertad para cambiar su residencia" (Constitución Política de la República Popular China, 1954).

Efectivamente, el reglamento de 1958 fue elaborado con el propósito de reducir los flujos migratorios hacia las principales ciudades, puesto que la llegada de migrantes podría provocar manifestaciones y desordenes sociales debido al probable aumento del desempleo, considerando el exceso de mano de obra y los costos que esto implicaría en la provisión de servicios sociales. A la vez, significaría un revés para la economía socialista planificada, pues esta dependía de un fuerte control de las zonas rurales y urbanas (Lu, 2002). El Estado estaba concentrado en el macroproceso de industrialización, que pretendía ser alcanzado a través del "Gran Salto Adelante" (Chan, 2001) el cual buscaba, mediante un conjunto de medidas económicas, políticas y sociales, la transformación de la sociedad china.

Una de las medidas relevantes de este periodo fue la transformación de la producción agrícola $^{6}$ que, pese a sus vaivenes, permitió abastecer a las ciudades de alimentos y materias primas, considerando que el porcentaje de población rural en 1960 era de un 83,79 \% (Banco Mundial, 2018b). En aquel tiempo, la gente del campo no estaba impedida de trasladarse a las ciudades, puesto que no existían acciones coercitivas, las que solo posteriormente fueron aplicadas. De este modo, el aumento masivo de

\footnotetext{
6 Según Mukherjee (1972), durante el "Gran Salto", las zonas agrícolas de China experimentaron transformaciones en términos de propiedad y configuración de mercados locales. La instauración de las comunas agrícolas (de carácter colectivo) en desmedro de la parcelación privada redujo los incentivos de producción. Esto hizo que China pasara de ser exportador de granos a importador, debido al déficit de producción, el cual fue corregido gracias a la reinstauración de las parcelaciones privadas y reduciendo el número de comunas de producción agrícola.
} 
población urbana, a fines de la década de 1950, llevó al sistema estatal de raciones de alimentos al borde del colapso, preocupando profundamente a la cúpula del Partido Comunista de China (PCCh) de perder el control social. A comienzos de 1960, el hukou fue aplicado de forma enérgica, teniendo como consecuencia la prohibición de compra de alimentos, la adquisición o alquiler de propiedades, el acceso a empleo y a beneficios sociales como salud y educación fuera de la zona de residencia. Asimismo, se deportó población de forma masiva hacia las zonas rurales, consolidando una sociedad dual (Wang, 2005, septiembre) en la que las personas del campo se vieron en desventaja respecto a sus conciudadanos urbanos. Cabe notar que la realidad en las zonas rurales era mucho más cruda, situación que contrastaba con la de los empleados estatales de las ciudades, quienes gozaban de cierta estabilidad y acceso a servicios que los granjeros no tenían.

La forma de organización territorial y el control mediante el sistema hukou fue desplegándose por toda China hasta alcanzar una cobertura a nivel nacional. El gobierno permitió los traslados de hukou en casos especiales; no obstante, no fue una posibilidad abierta a todos los ciudadanos. Cerca de 25 millones de campesinos y trabajadores que habían migrado a las ciudades durante la década de 1950 fueron presionados por el PCCh para volver a sus tierras nativas (Mukherjee, 1972).

Las medidas puestas en práctica para hacer efectivo el racionamiento de alimentos y el estricto control policial intrarregional contuvieron las presiones de la migración dentro del país, especialmente hacia Beijing y Shanghái. Al igual que el sistema propíska ${ }^{7}$ de la Unión Soviética, el sistema hukou proporcionó una institucionalidad para mantener a los campesinos en la granja, produciendo recursos agrícolas y abasteciendo al sector urbano de alimentos y materias primas.

En 1962 se impuso una cuota de control que determinó el límite de transferencia hukou, que no podía exceder el $1,5 \%$ del tamaño de la población local existente para cualquier área. Dado que la economía en este periodo carecía de un mercado funcional en casi todos los aspectos, los migrantes irregulares no tenían medios para sobrevivir en las ciudades sin la autorización estatal, pues la provisión de alimentos se encontraba en manos del gobierno.

La migración no autorizada por el Estado se vio fuertemente reducida en ausencia de alternativas de mercado y vinculando el hukou con la planificación económica socialista. En cambio, las migraciones políticas y económicas planeadas dominaron la movilidad de la población durante la era maoísta. (Young, 2013, p. 43).

Los últimos años del gobierno de Mao estuvieron marcados por disputas internas en el PCCh, donde la Banda de los Cuatro, facción radical del maoísmo y la facción moderada de Zhou Enlai y Deng Xiaoping, se disputó el poder. No obstante, posterior a

\footnotetext{
${ }^{7}$ Sistema de control regional de población en la ex-Unión Soviética que correspondía a un permiso de residencia o un registro poblacional.
} 
la muerte de Mao, la figura de Hua Guofeng - perteneciente al radicalismo maoísta- no logró posicionarse como sucesor en el cargo de presidente y de jefe de la Comisión Militar. Deng Xiaoping impuso sus ideas, dando la espalda a la revolución permanente, al tiempo que desafió a China a trabajar mejor que en la restauración Meiji en Japón (Kissinger, 2011), pues la facción que representaba Xiaoping proponía una renovación de las ideas maoístas, marcando con ello una ruptura en el desarrollo económico, político e institucional del país. Esto tuvo efectos en el sistema hukou, a causa del conjunto de reformas económicas modernizadoras que se desarrollaron en este periodo.

Tal como fue dicho, el segundo momento relevante en el funcionamiento del sistema hukou fue durante el gobierno de Deng Xiaoping. En el marco de las reformas socialistas de mercado implementadas, este gobierno se caracterizó por la gestación de un sistema de dos vías. En una, se desarrollaron elementos capitalistas de producción industrial en las ciudades y, en la otra, en el campo, persistieron los lineamientos político-económicos centralizados del socialismo (Wu, 2005).

La estrategia económica de industrialización adoptada por China junto con el sistema hukou consolidó una sociedad económica y socialmente dual. Por un lado, las ciudades y el sector industrial tuvieron carácter prioritario para la nación, pues allí se desarrollaron elementos capitalistas como empresas privadas, y los trabajadores tuvieron acceso al bienestar social en las empresas estatales y al disfrute de beneficios de diferente índole. Por otro lado, los campesinos estaban ligados a la tierra, cuyo desafío era producir un superávit agrícola con la finalidad de abastecer las altas demandas de las ciudades industrializadas (Chan, 2001), actividad para la cual no se contaba con inversión estatal suficiente en las diferentes áreas, tanto productivas como sociales. Además, el gobierno obligaba a los campesinos a entregar una cuota de producción de granos, hortalizas y todo tipo de productos de la tierra, con el propósito de cumplir con el abastecimiento de las zonas urbanas.

Entre 1977 y 1984 se eliminó el sistema de granjas colectivas, que fue reemplazado por la introducción de los sistemas de responsabilidad familiar. ${ }^{8}$ Esto dio paso, además, a la creación de mercados locales para el intercambio de productos que a la larga estimuló y diversificó la producción agrícola. Al decir de García (2000), en esencia, este sistema de responsabilidad consiste en que el Estado cede en usufructo a una familia, una determinada porción de tierra apta para el cultivo, que le es asignada en función de varios criterios, con el compromiso de entregar una determinada cuota de producción para favorecer su orientación hacia el mercado.

\footnotetext{
${ }^{8}$ Método de gestión que persigue repartir beneficios y cargas entre el Estado, la familia campesina y la colectividad. Sin alterar el régimen de la propiedad de la tierra y de otros medios básicos de producción que continuaron en manos del Estado, el nuevo sistema se fue liberalizando cada vez más hasta reducir aquella propiedad a una cuestión de tipo formal. Esta posibilidad de comercialización directa actúa como un eficaz estímulo para los productores. Si en el período comprendido entre 1953 y 1978 el aumento de la producción agrícola fue de un 3,2\% anual, entre 1978 y 1982 fue de un 7,5\%. En este último período los ingresos per cápita de los campesinos pasaron de 134 a 270 yuanes. La prosperidad rural conoció así, hasta mediados de la década de 1980, un avance notable (García, 2000).
} 
En otro ámbito, en las ciudades se combatió el desempleo mediante las empresas del pueblo, mientras el sistema hukou mantuvo los flujos migratorios estáticos para no sobrepoblar las ciudades de campesinos migrantes. Esto, junto con el régimen de racionamiento urbano, fueron las principales barreras para contener la presión migratoria campo-ciudad.

Durante 1979 se crearon cuatro Zonas Económicas Especiales (ZEE) ${ }^{9}$ a lo largo de la costa oriental, las cuales se posicionaron como plataformas de intercambio económico de China con el mercado asiático. Dotadas de infraestructura terrestre, naviera y aérea, se establecieron como áreas para el desarrollo de negocios de corte capitalista, permitiendo consolidar el sistema de dos vías (Furlong, Netzahualcoyotzi y Hernández, 2016). La desgravación tributaria y los incentivos económicos atrajeron empresas extranjeras a instalar sus fábricas en el país, generando un aumento de la Inversión Extranjera Directa (IED), medidas económicas que posicionaron a China como el mayor receptor de IED de los países en vías de desarrollo (Whyte, 2012). ${ }^{10}$

Debido a la falta de mano de obra, entre 1978 y 1985, la población urbana creció de 172 a 251 millones. A mediados de la década de 1980 los migrantes se volvieron vitales para el desarrollo de la economía de las ZEE, pues eran contratados, fundamentalmente, en el área de construcción, de los servicios domésticos y hoteleros, de las ventas y manufacturas y, además, constituyeron mano de obra atractiva para las empresas privadas al no tener obligaciones sociales con estos trabajadores (Young, 2013). Por otra parte, la vulnerabilidad social que generó el sistema hukou a los migrantes campesinos, al negárseles el acceso a derechos sociales por residir fuera de su zona de pertenencia, fue un factor de rentabilidad para las empresas privadas, ya que se trataban de personas dispuestas a acceder a puestos de trabajo por ingresos bajo el mínimo establecido.

\footnotetext{
${ }^{9}$ En la provincia de Guangdong (Shenzhen, Zhuhai, Shantou) y Fujian (Xianmen).

${ }^{10}$ Actualmente solo es superado por Estados Unidos y Países Bajos, según fuentes del Banco Mundial (2018a).
} 


\section{Gráfico $\mathrm{N}^{\circ}$ 1: IED versus porcentaje de población urbana}

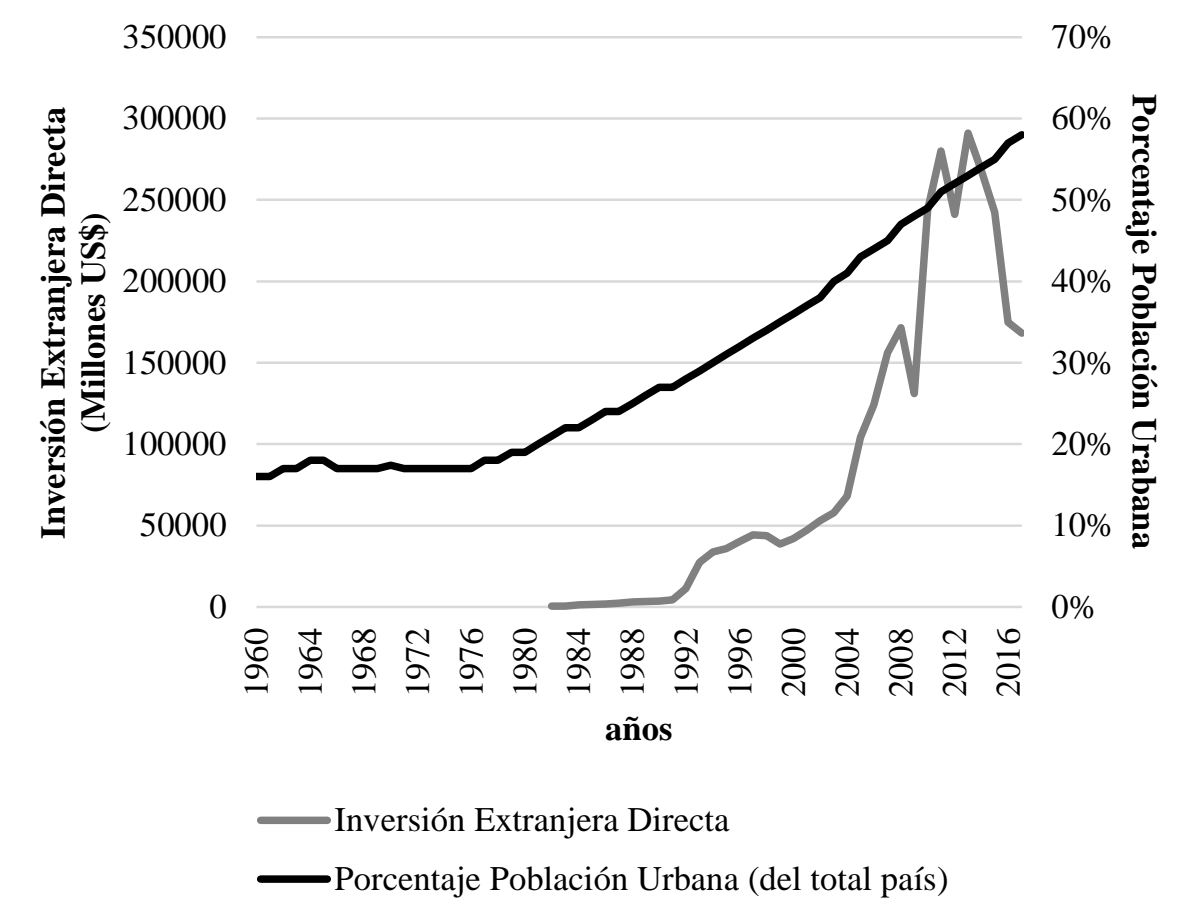

Fuente: elaboración propia basada en datos del Banco Mundial (2018b) y de National Bureau of Statistics of China (2016). ${ }^{11}$

En el Gráfico $\mathrm{N}^{\mathrm{o}} 1$ se puede observar el aumento sostenido de la población urbana total (personas registradas y no registradas), la que no había mostrado una variación considerable durante el gobierno de Mao. Con las políticas económicas de la administración de Deng Xiaoping, la migración se dinamizó de tal modo, alcanzando un crecimiento constante. A su vez, la IED, no presenta un aumento sostenido como el de la población urbana, pero sí, su tendencia es al alza desde la década de 1990. Esto, producto de las políticas económicas, con la excepción de la crisis de 2008, por lo que es posible, como primera aproximación, identificar un grado de relación. Lo anterior da cuenta de la importancia de la migración rural-urbana en el desarrollo y diversificación de la economía china, y pese a las restricciones que establecía el sistema hukou, los flujos migratorios avanzaron hacia las ciudades y los campesinos se trasladaron contrariamente a las barreras institucionales que imponía el sistema.

Un cambio de trascendental importancia se produjo a inicios de la década de 1980, cuando se gestó un proceso de descentralización fiscal y administrativa que dotó a las municipalidades del proceso de gestión migratoria. Esta medida dio pie a una administración heterogénea del sistema, acorde a las necesidades locales de cada municipio (Zhang y Li, 2016).

\footnotetext{
11 Este gráfico considera el dólar a precios de marzo de 2019. El porcentaje de población urbana comprende toda la población que reside en las ciudades, independientemente de su tipo de hukou.
} 
Otras medidas implementadas durante este período para proveer a las zonas urbanas de mano de obra, fue la implementación de la tarjeta de identidad ciudadana (TIC), que reemplazó al libro que registraba los hogares de los ciudadanos en cada administración local. Del mismo modo, se implementó un certificado de residencia temporal, de dos tipos: población temporal convencional -personas externas que brindan servicios domésticos, estudios o visitas familiares-y población temporal -personas externas que buscan empleo en sectores manufactureros y de servicios.

La creación de las ZEE generó alternativas de empleo fuera de las empresas estatales, las que discriminaban y no contrataban a trabajadores con hukou agrícola. Evidentemente, la entrada de capitales extranjeros a China, la libertad de contratación de las nuevas empresas de propiedad privada y el levantamiento de la restricción en el acceso a los alimentos abrieron un espacio para los trabajadores con hukou agrícola, permitiéndoles trabajar, pero sin acceder a la protección básica brindada por el Estado. En la medida que el crecimiento de las alternativas de mercado aumentó, la trasgresión de la regulación migratoria interna también se acrecentó (Young, 2013).

La necesidad de mano de obra en las ZEE dinamizó el proceso migratorio interno contenido por el sistema hukou, teniendo como consecuencia la introducción de una nueva modificación por parte de Beijing, en 1985. El cambio en "el permiso de residencia temporal" (Young, 2013) se introdujo con el propósito de mantener el control de los flujos migratorios, permitiendo a las personas poseedoras de hukou agrícola y no locales, trabajar y residir en zonas urbanas sin otorgarles un hukou urbano y local definitivo. Esta respuesta por parte de Beijing institucionalizó la flexibilidad de la migración, pero a su vez se posicionó como un nuevo método de control de los migrantes rurales, pues permitió al Estado conocer los lugares frecuentados, el tiempo de estadía, entre otras informaciones. Esto, principalmente, porque para establecer contratos de alquiler o alojamiento en hoteles era necesaria la identificación con la tarjeta hukou.

A medida que las personas del campo comenzaron a trasladarse a las ciudades, gracias al permiso temporal, la estructura de la fuerza de trabajo cambió de forma radical. En 1978 se registraba un $71 \%$ de personas empleadas en el sector primario, mientras el otro $29 \%$ se distribuía entre el sector secundario y terciario, industria y servicios, respectivamente. Más tarde, hacia el año 2000, con la consolidación del proceso de industrialización y la proliferación de empresas privadas, producto de las reformas económicas, se produjo un explosivo aumento en el nivel terciario y secundario, llegando en 2016 a abarcar cerca del $60 \%$ de las personas empleadas en China. 


\section{Gráfico $\mathrm{N}^{\circ}$ 2: Porcentaje de personas empleadas en China según sector económico}

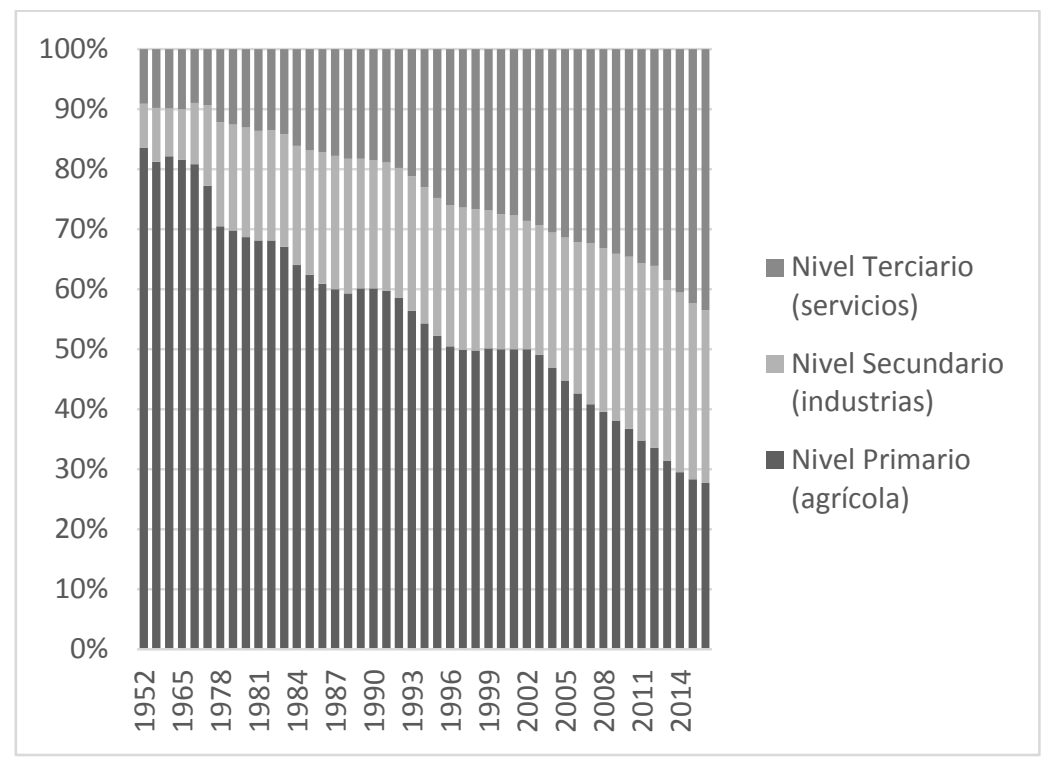

Fuente: elaboración propia basada en datos de National Bureau of Statistics of China (2016).

El período de Deng Xiaoping terminó con un país abriéndose al llamado milagro económico chino. La consolidación del proceso de apertura económica y la incorporación de la empresa privada en el mercado desplegaron un espacio para los trabajadores rurales, del cual el Estado no tuvo control en su totalidad. Las fuerzas de mercado empujaron a los campesinos a buscar nuevas oportunidades en las ciudades, no obstante, la existencia del sistema hukou los mantuvo siempre desprovistos del acceso a una ciudadanía plena, pese a las transformaciones institucionales, las cuales no intervinieron en las consecuencias del sistema de control de la población.

\section{El sistema hukou en el siglo XXI}

Las políticas de la administración de Deng Xiaoping beneficiaron a las áreas urbanas a expensas del campo, en tanto que la creación de las ZEE y la introducción de mecanismos de mercado potenciaron fundamentalmente el desarrollo de las áreas urbanas costeras de China. No obstante, en la década de 1990, como puerta al siglo XXI, la nueva administración de Jiang Zeming estableció objetivos regionales mediante la provisión de fondos adicionales para la China occidental, teniendo como foco los condados más pobres del país (Wade, 2007). Por otra parte, ciudades como Beijing y Shanghái establecieron mecanismos de conversión de hukou con requisitos muy altos, con el propósito de atraer a personas talentosas y con capacidad de inversión en las ciudades. Tales medidas tuvieron el propósito de alivianar los costos locales de incorporación de estos ciudadanos en materias de salud, educación y vivienda, dado que, al ser personas con recursos, no requerían de ayuda estatal para su inserción en la vida urbana (Wade, 2007). 
La inversión en los sectores pobres del país buscó dotar a los municipios más desprovistos de mejores instalaciones públicas, mientras que en las grandes ciudades, como Beijing y Shanghái, se impulsaron "reformas profundas" al sistema con la introducción del hukou "Sello Azul" ${ }^{12 "}$ y "Sello Verde ${ }^{13}$ ". En tanto, en las urbes medianas y pequeñas, el Consejo de Estado aprobó en 1997 los "Planes experimentales de reforma del sistema hukou en ciudades y pueblos pequeños" (Wang, 2004).

Esta reforma incluyó principalmente la flexibilización de las restricciones de la migración interna, exclusivamente para un grupo seleccionado de personas, con talento, altamente educadas, trabajadores calificados y personas con altos niveles de ingresos. En segundo lugar, se eliminaron las cuotas de migración rural-urbana en las ciudades y pueblos pequeños, ${ }^{14}$ lo que posibilitó que cualquier persona que trabajara en estas ciudades tuviera un ingreso estable y viviera por al menos dos años con registro agrícola, pudiendo calificar para convertirse en residente local. En provincias como Fujian, Guangdong, Jiangsu y Zhejiang se abolió la distinción entre hukou agrícola y no agrícola, manteniendo la de hukou local y no local, registrando, por tanto, a las personas como residentes locales o temporales.

Un ejemplo de la aplicación de estas reformas las llevó a cabo el gobierno municipal de Zhengzhou. Esta municipalidad emitió una ordenanza que permitió que las personas solicitaran residencia permanente en la ciudad, con el requisito de compra de vivienda, o de ser personas con alto capital humano o personal calificado. Dos años después de la implementación de esta medida, la ciudad registró 150.104 personas nuevas (Jianjie, 23 de septiembre de 2004). Sin embargo, la capacidad de la ciudad fue sobrepasada en la provisión de servicios sociales, lo cual también se reflejó en el aumento de las matrículas escolares, llegando las aulas a albergar la cantidad aproximada de 80 estudiantes por sala. Las autoridades se vieron presionadas a congelar la reforma, principalmente porque el hacinamiento estaba provocando la razonable molestia de los padres (Jianjie, 23 de septiembre de 2004).

En consecuencia, a mediados de 2002 Beijing ordenó detener esta ola de reformas locales en espera de "más instrucciones", principalmente, por la falta de fondos e infraestructura para sostener la educación, la salud y el bienestar social, que permitiera incorporar rápidamente a los nuevos ciudadanos urbanos (Jianjie, 23 de septiembre de 2004). La política del hukou "Sello Azul" fue abolida en el mismo año por Shanghái, esencialmente, porque no logró atraer a los migrantes más calificados (Huang, 2014).

\footnotetext{
${ }^{12}$ El hukou "Sello Azul" es un tipo de tarjeta que se incorporó para atraer talentos, empresarios y capital humano avanzado. Mediante este tipo de identificación, las personas accedían a la ciudadanía plena en la ciudad; no obstante, para el caso de empresarios o personas naturales con capacidad económica requerían realizar una inversión en la ciudad de destino, lo que brindaba un valor al acceso de este tipo de hukou.

${ }^{13}$ El hukou "Sello Verde" se utilizó principalmente para personas extranjeras que vivían en China, grupos chinos étnicos de ultramar (Macao y Taiwán) y también chinos que poseían doble nacionalidad y estaban radicados en el exterior, cuya mayoría de destinatarios correspondió a científicos, expertos y empresarios. ${ }^{14} \mathrm{Se}$ considera pequeñas y medianas ciudades a las aglomeraciones urbanas entre quinientos mil y un millón de habitantes.
} 
Con $\mathrm{Hu}$ Jintao en el poder, en el 2003, el desarrollo rural se convirtió en el primer punto de la agenda de su gobierno, con el lema "Estableciendo el nuevo campo socialista" (Jianshe shehui zhuyi xin nongcun). Las estrategias de las décadas pasadas abordaron la pobreza extrema vinculada a aspectos como alimentación y vestimenta, por lo que el enfoque del nuevo gobierno apuntó a una comprensión amplia de la pobreza, particularmente rural, cuyo propósito fue nivelar la disparidad entre zonas urbanas y rurales (Wade, 2007). En el mismo año, se abolieron las medidas coercitivas de repatriación forzada, las que habían sido empleadas principalmente para retornar a migrantes vagabundos mediante detenciones policiales. Esta decisión tuvo como consecuencia el aumento del número de personas en situación de calle en las grandes ciudades como Beijing, del mismo modo que permitió que se mantuvieran constantes los flujos migratorios hacia las zonas urbanas (Wang, 2005, septiembre).

Posteriormente, durante dos sesiones del Congreso Nacional del Pueblo, en marzo de 2005, el Ministerio de Seguridad Pública anunció que se aceleraría el trabajo legislativo para la nueva Ley de Registro de Hogares (hukou), que aboliría gradualmente la distinción urbano-rural (Shan, 11 de mayo de 2007). En este período hubo avances en torno a medidas experimentales en algunas ciudades del país, siendo los resultados poco alentadores. Esto, debido al impacto económico que el sostenimiento de migrantes rurales provocaba en las arcas fiscales locales. No obstante, a pesar de los intentos por buscar vías para la reforma al sistema, el gobierno tenía en perspectiva incorporar, en los siguientes veinte años, a 300 millones de campesinos en las ciudades (Consejo de Estado de la República Popular China, 2006). 


\section{Gráfico $\mathbf{N}^{\circ}$ 3: Porcentaje de población con hukou no agrícola y población urbana total (1978-2010)}

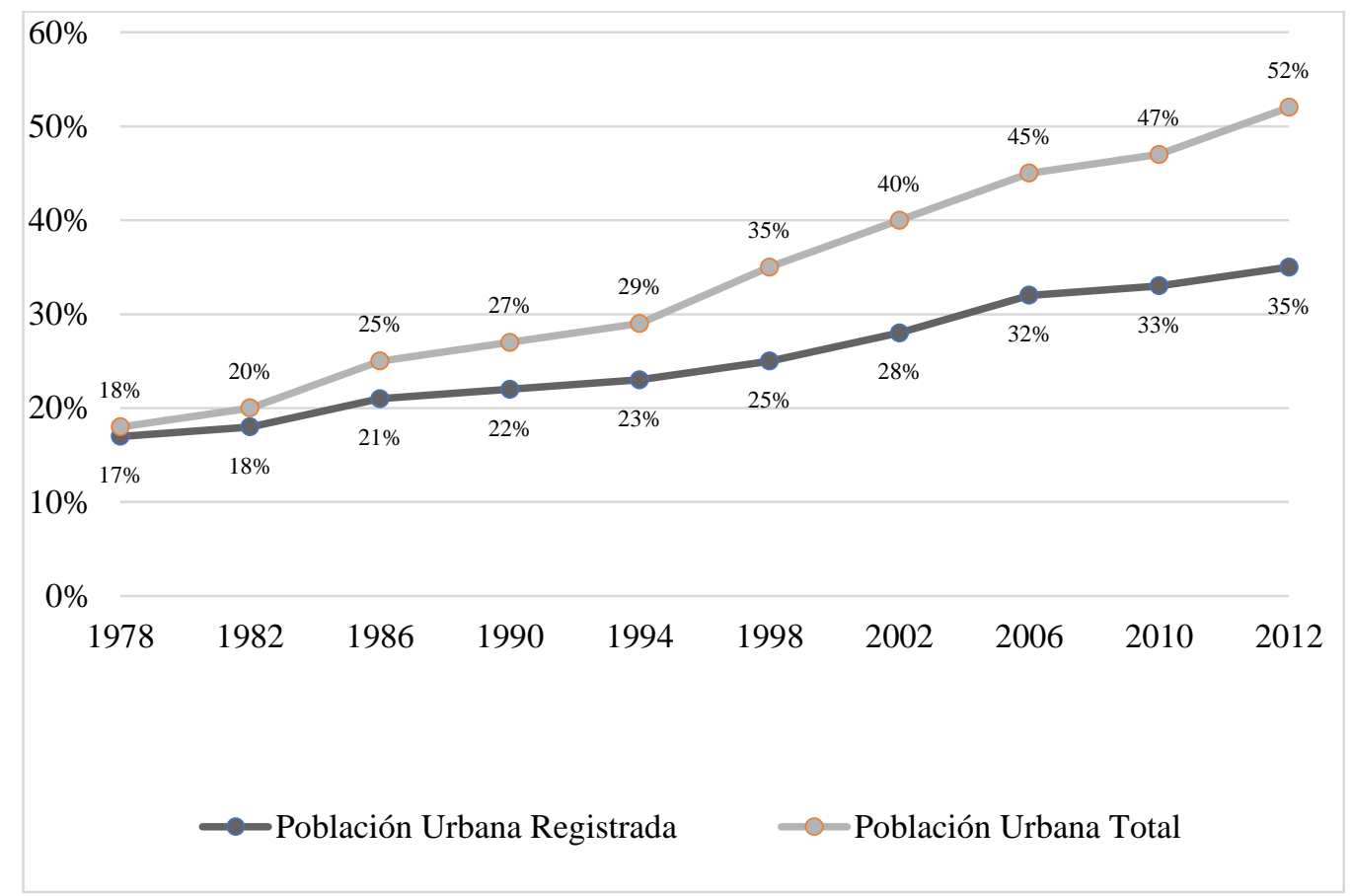

Fuente: elaboración propia basada en datos de la National Bureau of Statistics of China (2010).

Avanzado el siglo XXI, para el año 2012 la población con "registro de hogar no agrícola" llegó a un $35 \%$ a nivel nacional, en tanto que el total de población urbana registró un $51 \%$. De esta cantidad, un 17 \% constituía población "flotante", es decir, que se encontraba de forma transitoria en las ciudades o vivía al margen del Sistema de Registro de Hogares.

El gobierno de $\mathrm{Hu}$ Jintao no logró consolidar políticas sólidas que abordaran de forma integral el problema de desigualdad económica y social entre las zonas rurales y urbanas del país. Como asimismo, tampoco logró la incorporación efectiva de población migrante en las ciudades según lo proyectado. El porcentaje de población flotante que se encontraba al margen del ejercicio pleno de ciudadanía en las zonas urbanas se aproximaba a la considerable cifra de 250 millones de personas en 2010 (National Bureau of Statistics of China, 2010).

La heterogeneidad en la gestión del Registro de Hogares a nivel local y la capacidad de los municipios para implementar modificaciones al sistema varían en función del contexto local de cada municipio, dependiendo de si son urbanos o rurales, de su localización geográfica, de su actividad económica, entre otros factores. Ciudades como Fujian, Guangdong, Jiangsu y Zhejiang, mencionadas anteriormente, dan cuenta de dicho problema.

A finales de la década de 2000, Beijing es la ciudad con más restricciones para la población proveniente del campo, dado su alto estándar de vida, pues su condición de 
municipio bajo control directo del gobierno central le otorga una posición favorable dentro del esquema financiero del gobierno, siendo una municipalidad con un gran cantidad de recursos para invertir en el bienestar social de sus ciudadanos, llevando al gobierno a aplicar medidas más restrictivas con el propósito de no sobrepoblar la ciudad. Pese a aquello, habitan de igual forma trabajadores migrantes rurales, junto a sus familias, a contracorriente de las exclusiones de acceso a derechos formales. Así por ejemplo, hubo agrupaciones de migrantes que levantaron escuelas alternativas para sus hijos.

Sin el permiso de residencia, no tienen derecho a ser escolarizadas en la capital. Sólo podrían llevarlas a una escuela para hijos de emigrantes, que a menudo son clandestinas, con instalaciones paupérrimas y una enseñanza mucho peor, o hacer una donación a un colegio público - literalmente, dar un sobre a la dirección - y pagar unas tasas de matrícula mucho más altas. Es la estrategia de las escuelas: como no quieren niños del campo que «ensucien» su reputación, filtran cobrando. (Fuentes, 2012, p. 182).

A pesar de la exclusión que sufren las personas sin autorización para asentarse en grandes urbes, estas han generado diversos medios alternativos de subsistencia, al margen de cualquier norma o regulación por parte del gobierno. Las escuelas alternativas son parte de este fenómeno, en la cual el fragmento anterior da cuenta de la clandestinidad en la que operan estos establecimientos, profundizando y agravando aún más las consecuencias de la exclusión social institucionalizada por este sistema de control migratorio.

\section{El nuevo plan de urbanización y el sistema hukou}

Una vez concluido el gobierno de Hu Jintao en 2013, Xi Jinping se posicionó como la figura líder de la nación asiática, asumiendo el mandato de todo el país. Durante los primeros años, el gobierno central promulgó un ambicioso programa conocido como "El Nuevo Plan de Urbanización 2014-2020" (Consejo de Estado de la República Popular China, 2014).

Este plan se promulgó en un contexto en que, tal como dijimos antes, el porcentaje de población urbana superaba a la rural, constituyéndose en 2012 en el 52,6 \%, el cual correspondía en un 17,3 \% a población migrante rural no registrada, siendo un 35,2 \% ciudadanos urbanos locales (Consejo de Estado de la República Popular China, 2014). Es decir, una de cada tres personas de las ciudades era migrante rural.

El plan promulgado concentró su atención en el desarrollo integral de las personas. China ha gestado un proceso de urbanización enfocado en la tierra, que ha creado beneficios económicos y sociales, pero que a su vez ha tenido impactos adversos. El rápido crecimiento económico y la apertura a los mercados internacionales desencadenaron un dramático proceso de urbanización de tierras agrícolas, pasando las tierras urbanizadas a registrar un crecimiento de $7.438 \mathrm{~km}^{2}$ a $45.566 \mathrm{~km}^{2}$, con una tasa 
de crecimiento anual de un $6 \%$ entre 1981 y 2012. Como era de suponer, este proceso de urbanización de tierras no estuvo armoniosamente acompañado de una densificación urbana, por lo que el número de ciudades creció de 2.173 en 1980 a 20.113 en 2012 (Chen, Liu y Lu, 2016). Estos patrones de urbanización insostenibles en el tiempo han producido de esta forma un descenso de las tierras cultivables y, por consiguiente, han puesto en riesgo la seguridad alimentaria del país (Fang, Zhenwei y Meiyan, 2016). El aumento del número de ciudades en la zona central de China no ha sido una medida eficiente, debido a que la mayoría de los trabajadores migrantes ha preferido un asentamiento en las franjas costeras desarrolladas.

Beijing, Tianjin, Hebei, el delta del río Yangtzé y el delta del río Perla han congregado en 2014 el $18 \%$ de la población en el 2,8 \% de la superficie de China (Consejo de Estado de la República Popular China, 2014), concentrando el $36 \%$ del PIB. Por otra parte, el nivel de calidad de los servicios públicos de estas aglomeraciones urbanas son los más altos del país. No obstante, la integración de grandes cantidades de personas de procedencia agrícola es una meta difícil de conseguir. En estas zonas es donde se aplica de manera más estricta las distinciones entre personas locales y no locales, con el fin de proteger la calidad de vida y los servicios de la población local registrada (Fuentes, 2012).

El Nuevo Plan para la Urbanización proyectó trasladar al año 2020 a 100 millones de personas de zonas rurales a las ciudades, para llegar así al $60 \%$ de urbanización, con el fin de aumentar la proporción de recursos per cápita en el campo, promoviendo, al mismo tiempo, la mecanización y crecimiento en escala de la producción agrícola.

Las discusiones académicas acerca de la nueva urbanización han girado principalmente en torno a la aglomeración de la población, tema sobre el que las investigaciones han correlacionado positivamente la urbanización con el aumento de tierras cultivables, sugiriendo que mientras más aumente la urbanización, más tierras cultivables habrá (Fang, Zhenwei y Meiyan, 2016). No obstante, el gobierno central señala todo lo contrario, ya que el plan apunta al desarrollo de nuevas aglomeraciones urbanas en el centro y el oeste de China, pues las ciudades del este se encuentran densamente pobladas y con su capacidad de carga ambiental sobrepasada, por lo que es necesario urbanizar otras zonas menos pobladas (Consejo de Estado de la República Popular China, 2014).

Las directrices emanadas de este plan señalan que el empleo y residencia, legal y estable con contratos de arrendamiento, serán condiciones previas para el asentamiento de personas en las ciudades. Por otro lado, se liberalizará completamente el asentamiento de personas en pueblos y ciudades pequeñas, mientras que en ciudades con quinientos mil a un millón de habitantes se liberalizará de manera ordenada y racionalmente. Las ciudades medianas y grandes, de un millón a tres millones y de tres a cinco millones de personas, pueden establecer como requisito adicional la participación en el seguro social urbano, sin exceder los cinco años. Las megaciudades, con una población de más de cinco millones de personas, pueden adoptar un sistema de puntos para establecer un canal de asignación que controle la escala y el ritmo de la urbanización (Consejo de 
Estado de la República Popular China, 2014). En términos de cobertura social se indica que se alentará a los trabajadores migrantes a integrarse a distintos tipos de seguros, que van más allá del seguro médico básico urbano, estableciendo un sistema de vejez básico unificado para residentes urbanos y rurales. Del mismo modo, propone ampliar la proporción de trabajadores migrantes que participan en el seguro de lesiones laborales, seguro de desempleo y seguro de maternidad. Al mismo tiempo, se promueve la cooperación entre el seguro comercial y el seguro social, como también, la idea de fomentar tipos de pensiones complementarias de atención médica y de seguro de salud (Consejo de Estado de la República Popular China, 2014).

En términos de acceso a las coberturas, los migrantes y sus familiares acompañantes son incluidos en el sistema de servicios de salud de la comunidad, brindándoles servicios de salud pública, como educación en salud, atención materno-infantil, vacunación, prevención de enfermedades infecciosas y planificación familiar (Consejo de Estado de la República Popular China, 2014).

Se señala, también, que las empresas deberán ofrecer a sus trabajadores migrantes, talleres de educación vocacional y capacitación en habilidades para un mejor desempeño. Los trabajadores deberán tener la capacidad de costear gastos personales de vivienda y alimentación, de acuerdo con las regulaciones para mejorar el proceso de integración en la sociedad urbana.

Además, el plan señala que todos los niveles de gobierno asumirán las responsabilidades financieras correspondientes y que, a su vez, apoyarán la mejora de la capacidad de los gobiernos municipales respecto a la prestación de servicios públicos en las zonas donde la población agrícola transferida esté asentada. En la misma línea, se propone la eliminación de las barreras institucionales para la estructura dual urbanorural, promoviendo el intercambio equitativo de elementos urbanos y rurales, junto con la asignación equilibrada de recursos públicos.

Asimismo, se plantea la implementación de un sistema de permiso de residencia de población flotante, para mejorar así la provisión de servicios públicos básicos, vinculados con las condiciones de residencia permanente. Junto con la modernización del sistema de levantamiento de información censal, el documento propone la integración del sistema de información territorial, a fin de construir un banco de datos de la población a nivel nacional (Consejo de Estado de la República Popular China, 2014). Esto da cuenta de la continuidad del Sistema de Registro de Hogares hukou, pues si bien se plantea un proceso de flexibilización en el asentamiento en las ciudades, el control se mantiene vigente, y la exclusión como mecanismo de desincentivo a sortear las barreras institucionales presenta elementos de persistencia, pues el Nuevo Plan de Urbanización considera la incorporación de migrantes internos en ciudades poco habitadas respecto a otras megaurbes, y en estas últimas los requisitos siguen siendo altos. A partir de aquello es posible plantear una incongruencia en torno al discurso y las directrices y medidas emanadas del gobierno central, dando cuenta de la ausencia de interés de asumir de manera directa y concreta el estado de desigualdad institucionalizada en el que habitan las y los habitantes de la República Popular China. 
En 2015, el país promulgó el XIII Plan Quinquenal, considerado el documento que guía los lineamientos de las políticas públicas en función de los objetivos del Estado para alcanzar el desarrollo económico y social. Dicho plan señala que se progresará en los esfuerzos para ayudar a las personas que han migrado del campo a las ciudades a insertarse en la vida urbana, con énfasis en las familias y no en las personas individualmente. La prioridad está centrada en personas que hayan vivido en un área urbana por al menos cinco años y hayan trasladado a sus familias con ellos; estudiantes que estén ingresando al siguiente nivel de educación en un área urbana y al personal de Fuerzas Armadas. Asimismo, se dispone que las ciudades provinciales deberán levantar todas las restricciones correspondientes para garantizar la residencia a estudiantes universitarios, trabajadores especializados, graduados y a estudiantes que hayan regresado de estudios fuera del país. Por otra parte, se garantizará la residencia en grandes ciudades a aquellos que posean títulos técnicos y profesionales. Además, las ciudades grandes y medianas no deberán restringir el acceso a la residencia permanente ni a beneficios relacionados, como por ejemplo la compra de una casa, inversiones y un sistema de acumulación de puntos.

Otra disposición del XIII Plan Quinquenal apunta a que las megaciudades deberán implementar políticas diferenciales para garantizar la residencia permanente, usando como criterios de elegibilidad: el empleo estable y legítimo, la renta y número de años de participación en sistemas de seguro social urbano y los años de residencia. Se enfatiza en que los gobiernos municipales deberán asumir mayor responsabilidad y garantizar residencia urbana a un número de personas cada vez mayor (Consejo de Estado de la República Popular China, 2015).

Los postulados del Plan Quinquenal en materia de urbanización siguen la lógica del Nuevo Plan para la Urbanización, promoviendo la integración de personas no locales en las ciudades. El gobierno de Xi Jinping ha sido fuerte en promover un proceso de urbanización armonioso, asumiendo las dificultades que el control de la migración interna ha generado. Si bien los primeros años de su gobierno estuvieron marcados por el Nuevo Plan para la Urbanización y el XIII Plan Quinquenal, iniciativas todas que hicieron suyos los desafíos del gigante asiático, no obstante, reincidentemente el objetivo de incorporar a cien millones de migrantes a la vida en las ciudades con todos los derechos de un residente urbano ha sido una tarea compleja de llevar a cabo. 


\section{Gráfico $\mathrm{N}^{\circ}$ 4: Porcentaje de población con hukou urbano y población urbana total} (1978-2019)

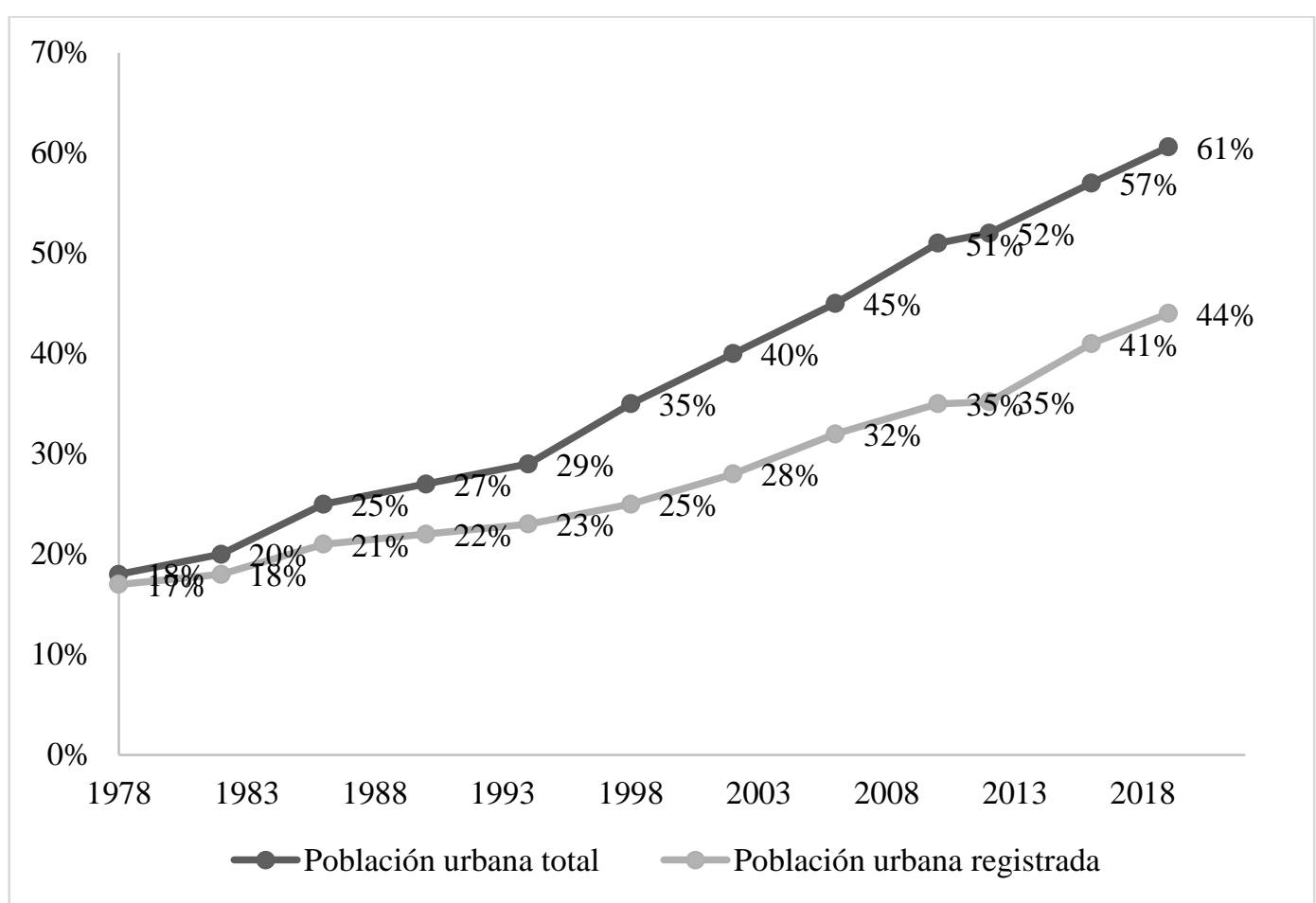

Fuente: elaboración propia basada en datos de National Bureau of Statistics of China (2019).

El porcentaje de población urbana total en China ha aumentado nueve puntos porcentuales entre 2012 y 2019, como asimismo, el porcentaje de población urbana legal registrada. Si bien se ha cumplido el objetivo de alcanzar un $60 \%$ de urbanización antes de 2020, la brecha entre residentes con hukou urbano y el total de residentes en las ciudades llegó a un $17 \%$ en 2019. ${ }^{15}$ Cifra no menor si se considera que es población sometida a las limitaciones en el ejercicio de la ciudadanía que genera el sistema hukou.

Por su parte las ciudades pequeñas y medianas de las regiones central y occidental están liberadas de las restricciones para solicitar hukou local. Sin embargo, en las megaciudades del delta del Río Perla se mantienen los requisitos, los cuales son solo accesibles para una élite, pues el umbral de acceso sigue siendo muy alto para los agricultores del campo (Sohu News, 12 de marzo de 2018).

Asimismo, en estas megaciudades la discriminación institucional en la educación de los niños migrantes sigue siendo un elemento preocupante (Sohu News, 12 de marzo de 2018). Desde finales de los noventa, el Ministerio de Educación ha emitido documentos en los que disponía a los municipios brindar educación obligatoria a los niños migrantes (Wu, 2013). No obstante, autoridades del organismo han reconocido que la no posesión de un hukou local dificulta que estos puedan acceder a la educación (Consejo de Estado

${ }^{15}$ Según indicadores de la Comisión Nacional de Desarrollo y Reforma (Sohu News, 22 de marzo de 2019. 
de la República Popular China, 2016). Sin embargo, en ciudades como Shijiazhuang, capital de Hebei, han eliminado por completo los requisitos para el asentamiento de personas, hecho histórico en la reforma al sistema hukou. Lo mismo ha ocurrido con la ciudad de Xi'an, que reformó los requisitos, abriendo la posibilidad de asentamiento a personas con un título universitario y de edad menor a 45 años (Sohu News, 22 de marzo de 2019).

Pese a lo anterior, las megaciudades siguen siendo las más atractivas para la población migrante, dadas las oportunidades de empleo, de recursos de bienestar, de atención médica, de educación y de infraestructura, entre otras. Las ciudades más pequeñas tienen menos oportunidades de empleo, por lo que a pesar de haber eliminado las barreras del sistema hukou, la lejanía con las principales urbes les juega como un elemento en contra (Wallstreetcn, 2019).

Es posible dar cuenta de que este sistema implementado desde la década de 1950, transformado al alero de los cambios políticos, económicos y sociales de la China Comunista durante los últimos 60 años, ha representado no solo la institucionalización de los procedimientos para el traslado interno en el país, sino también la institucionalización de prácticas discriminatorias, como el otorgamiento de residencia en ciudades a personas con mayor capital económico y cultural en desmedro de las personas más carentes de recursos, quienes a menudo, en ausencia de oportunidades en sus zonas de origen, acuden a las ciudades en búsqueda de mejores oportunidades.

El discurso que el gobierno de Xi Jinping ha planteado, en torno a combatir las desigualdades que produce el sistema, proponiendo mecanismos para la incorporación de personas del campo en las ciudades, solo reproduce lógicas discriminatorias que, a su vez, incentivan a profesionales y personas con un gran capital financiero a reasentarse en megaciudades. Por otra parte, el fenómeno adquiere un grado de complejidad mayor, pues se evidencia que la forma en la cual se aplica el sistema, difiere entre ciudades, donde factores como el ingreso económico de la ciudad y la cantidad de habitantes son condicionantes en la forma en que los municipios implementan y gestionan el sistema hukou.

\section{Conclusiones}

Los cambios políticos, sociales, económicos y culturales que han acompañado a la globalización en los primeros años del siglo XXI, también han impactado fuertemente en los movimientos de población, tanto a nivel internacional como interno de los países. Esto, producto de las transformaciones de las economías locales en respuesta a la reconfiguración de los países manufactureros a escala global.

La migración interna -campo-ciudad en el caso de la República Popular China- es un proceso tan complejo que posee distintas dimensiones de estudio, y como todo proceso migratorio tiene más de una mirada teórica y analítica. El recorrido realizado en el presente trabajo buscó aportar, desde una mirada centrada en la institucionalidad, la 
forma en que este sistema se desarrolló en función de las transformaciones del gigante asiático y cómo en el presente este continúa siendo la institucionalización de las limitaciones de los ciudadanos chinos en sus desplazamientos internos.

En la actualidad, a sesenta años de la implementación del sistema hukou, las condiciones del crecimiento económico de China han influenciado en su aplicación. El gobierno central ha debido reformular algunas de las bases del sistema en los distintos períodos abordados, disponiendo medidas para mantener el equilibrio entre los indicadores macroeconómicos y las necesidades de mano de obra migrante en las megaciudades, dado que estos espacios urbanos concentran el eje de la industrialización y son polos de atracción de migrantes rurales.

Durante el gobierno de Deng Xiaoping se abrió un espacio a la explotación de mano de obra barata por parte de empresas privadas, a expensas de la flexibilización en el acceso a las ciudades de manera provisional. Las fronteras internas levantadas por este sistema fueron sorteadas por muchos migrantes, sin embargo, las limitaciones al acceso a una ciudadanía plena han persistido. El control racional de los flujos, que ha buscado la atracción de capital humano a las ciudades, a través de las medidas empleadas en la última década continúan desarrollado un mecanismo de desigualdad institucionalizada para los habitantes de la República Popular China.

El Nuevo Plan para la Urbanización y el XIII Plan Quinquenal promueven la migración de personas talentosas y con alto capital humano hacia las megaciudades, contribuyendo finalmente a perpetuar la desigualdad económica y social a nivel intrarregional, privando a las ciudades intermedias y pequeñas de personas con capital humano que contribuyan a su desarrollo, como asimismo, responder a las aspiraciones personales de mejora y progreso, pese a que los mecanismos de incorporación de migrantes rurales en las ciudades propuestos por gobierno central no entregan a las administraciones municipales los recursos para costear su incorporación.

Desde una mirada institucional, este sistema se sitúa como la piedra angular de los procesos migratorios internos del país, donde es importante tener en cuenta su papel como condicionante de los movimientos de personas durante más de sesenta años. En la misma línea, las particularidades de su contexto y magnitud, junto con el hecho de que son los mismos ciudadanos chinos quienes se encuentran en posición de desventaja respecto a sus compatriotas con registro urbano, configuran lo ideográfico del fenómeno. Si bien este puede presentar características de índole similar a un proceso migratorio campo-ciudad -al poner el foco en los motivos que generan el desplazamiento-, la estructura institucional que norma estas movilidades configura este caso como único, en atención a las dimensiones que adquiere y que se han ido desarrollando desde su promulgación en 1958.

Finalmente, el sistema hukou en la China actual desempeña un papel significativo en términos migratorios, en cuanto a que el control de los movimientos poblacionales sigue siendo el principal motivo de su existencia. No obstante, su modernización es un desafío para cada nueva administración, especialmente, como factor del crecimiento económico 
$\mathrm{y}$, fundamentalmente, para mantener el control social que por décadas ha tenido el sistema.

\section{Referencias bibliográficas}

Abad, R. G. (2003). Un estado de la cuestión de las teorías de las migraciones. Historia Contemporánea, 26, 329-351.

Arango, J. (2003). La explicación teórica de las migraciones: luz y sombra. Migración y Desarrollo, octubre, (1), 1- 30. Recuperado de https://doi.org/10.35533/ myd.0101.ja

Banco Mundial (2018a). Población rural (\% de la población total) - China (gráfico). Banco Mundial datos. [En línea]. Recuperado de https://goo.gl/5GD3Fx

Banco Mundial (2018b). Inversión extranjera directa, entrada neta de capital (balanza de pagos, US\$ a precios actuales) - China. Banco Mundial datos. [En línea]. Recuperado de http://bit.do/eQqpP

Castles, S. (2002). Migration and community formation under conditions of globalization. International Migration Review, 36(4), 1143-1168. DOI: https://doi.org/10.1111/j.1747-7379.2002.tb00121.x

Castles, S., Miller, M. J., y Quiroz, L. R. M. (2004). La era de la migración: Movimientos internacionales de población en el mundo moderno. México: Universidad Autónoma de Zacatecas.

Chan, A. L. (2001). Mao's Crusade: Politics and Policy Implementation in China's Great Leap Forward. Oxford: Oxford University Press.

Chan, K. W. yBuckingham, W. (2008). Is China abolishing the hukou system? The China Quarterly, 195, 582-606. Recuperado de https://www.jstor.org/ stable/20192236? seq $=1$

Chan, K. W. y Zhang, L. (1999). The hukou system and rural-urban migration in China: Processes and changes. The China Quarterly, 160, 818-855. DOI: https://doi.org/10.1017/s0305741000001351

Chen, M., Liu, W. y Lu, D. (2016). Challenges and the way forward in China's newtype urbanization. Land Use Policy, 55, 334-339. DOI: https://doi.org/10.1016/j.landusepol.2015.07.025

Chung, E. A. (2017). Citizenship in non-western contexts. En A. Shachar, R. Bauböck, I. Bloemraad y M. Vink (eds.), The Oxford Handbook of Citizenship (pp. 432457). Oxford: Oxford University Press.

Constitución Política de la República Popular China [Const.]. 1954. (China). Recuperado de https://goo.gl/24CDyb 
Consejo de Estado de la República Popular China (2006). Se espera que las ciudades absorban 300 millones de agricultores. Recuperado de https://goo.gl/DR95QE

Consejo de Estado de la República Popular China (2014). Nuevo Plan Nacional de Urbanización (2014-2020). Recuperado de https://goo.gl/UV6cmr

Consejo de Estado de la República Popular China (2015). El XIII Plan Quinquenal para el Desarrollo Económico y Social de la República Popular China. Recuperado de https://goo.gl/a3eb4e

Consejo de Estado de la República Popular China (2016). ¿Cómo se hace realidad el sueño hukou? Recuperado de https://goo.gl/ic1Epw

Cornelius, W. y Rosenblum, M. (2004). Immigration and Politics. Center for Comparative Immigration Studies, UC-San Diego Working Papers.

Correa, G., y Núñez, R. (2013). Migración y exclusión en China: Sistema hukou. Problemas del Desarrollo, 44(172), 105-122. DOI: https://doi.org/10.1016/s0301-7036(13)71864-9

Davin, D. (1998). Internal Migration in Contemporary China. Londres: Palgrave Macmillan.

Durand, J., y Massey, D. S. (2003). The costs of contradiction: US Border Policy 19862000. Latino Studies, 1(2), 233-252. DOI: https://doi.org/10.1057/ palgrave.1st.8600022

Fan, C. C. (1997). Uneven development and beyond: regional development theory in post-Mao China. International Journal of Urban and Regional Research, 21(4), 620-639. DOI: https://doi.org/10.1111/1468-2427.00105

Fang, C., Zhenwei, G. y Wang, M. (2016). New urbanisation as a driver of China's growth. China's New Sources of Economic Growth, (1), 43-64. DOI: https://doi.org/10.22459/cnseg.07.2016.03

Fuentes, A. (2012). Cuando los chinos hablan: historias reales para entender a la futura potencia del mundo. Buenos Aires: Penguin.

Furlong, A., Netzahualcoyotzi, R., y Hernández, A. (2016). Las Zonas Económicas Especiales de China. Jiexi Zhongguo. Análisis y Pensamiento Iberoamericano sobre China (22). Recuperado de https://politica-china.org/secciones/ publicaciones/jiexi-zhongguo

García, J. R. (2000). Área económica China: apertura e inserción en la economía mundial: el área económica china; la incorporación de Hong-Kong y Macao al área económica China : problemas y perspectivas. Estudios Internacionales, 33(131-132), 3-64. DOI: https://doi.org/10.5354/0719-3769.2000.14919 
Greenwood, M. J. (1997). Internal migration in developed countries. Handbook of Population and Family Economics, 1, Part B, 647-720. DOI: https://doi.org/10.1016/s1574-003x(97)80004-9

Hollifield, J. F. y Wong, T. (2000). The politics of international migration. En C. Brettell y J. F. Hollifield, Migration Theory: Talking across Disciplines (pp. 227-288). Londres: Routdlege

Huang, Y. (2014). The continuity and changes of the hukou system since the 1990s: A critical review. En Z. Cheng, M. Wang y J. Chen (eds.), Urban China in the New Era (pp. 25-43). Berlín: Springer Heidelberg. DOI: https://doi.org/10.1007/9783-642-54227-5_2

Jianjie, T. (23 de septiembre de 2004). Zhengzhou, problema de la política de registro de hogares: grave sobregiro de los recursos de educación y transporte. Sohu News [en línea]. Recuperado de https://goo.gl/waMWDz

Kissinger, H. (ed.). (2011). China. Barcelona: Debate.

Li, C. (1996). Surplus rural laborers and internal migration in China: Current status and future prospects. Asian Survey, 36(11), 1122-1145. DOI: https://doi.org/ 10.1525/as.1996.36.11.01p0183y

Lu, Y. (2002). Structure and change: The household registration system in china after 1949 [1949 Nian Hou de Zhongguo Huji Zhidu: Jiegou yu Bianqian]. Journal of Peking University (Humanities and Social Sciences), 39(2), 123-130.

Mármora, L., y Calcagno, A. E. (2002). Las políticas de migraciones internacionales. Buenos Aires: Paidós.

Martínez, J. (2011). Migración internacional en América Latina y el Caribe. Nuevas tendencias, nuevos enfoques. D'AnàLisi GeogràFica, 58(3), 526-529.

Moyano, P. N. B. (2010). El estudio de las migraciones en la ciencia política. Un intento de sistematización. Ciencia Política, 5(9). Recuperado de https://revistas.unal.edu.co/index.php/cienciapol/article/view/17013

Mukherjee, P. C. (1972). Reforma agraria y producción agrícola en China. Estudios Orientales, 7(1), 44-76. Recuperado de https://estudiosdeasiayafrica.colmex.mx

National Bureau of Statistics of China (2010). China Statistical Yearbook 2010. Beijing: China Statistics Press. Recuperado de https://goo.gl/MuvWqB

National Bureau of Statistics of China (2016). China Statistical Yearbook 2016. Beijing: China Statistics Press. Recuperado de https://bit.ly/21KY25H

National Bureau of Statistics of China (2019). China Statistical Yearbook 2010. Beijing: China Statistics Press. Recuperado de https://bit.ly/2O7Vqmm

North, D. C. (1990). A transaction cost theory of politics. Journal of Theoretical Politics, 2(4), 355-367. 
Ravenstein, E. G. (1885). The laws of migration. Journal of the Statistical Society of London, 48(2), 167-235.

Reglamento de la República Popular China sobre el Registro de Hogares (Reglamento). 1958 (China). Recuperado de https://goo.gl/xwxsNX

Shan, S. (11 de mayo de 2007). Los inconvenientes del sistema de registro de hogares de China se están expandiendo. Epoch Times. Recuperado de https://goo.gl/9M7Ymr

Shen, J. (2013). Increasing internal migration in China from 1985 to 2005: Institutional versus economic drivers. Habitat International, 39, julio, 1-7. DOI: https://doi.org/10.1016/j.habitatint.2012.10.004

Singer, P. I. (1973). Economia política da urbanização: ensaios. Editora Brasiliense.

Sohu News (12 de marzo de 2018). Derechos urbanos de los agricultores chinos. Sohu News, s. p. [En línea]. Recuperado de https://goo.gl/ui58pU

Sohu News (22 de marzo de 2019). Este año, la tasa de urbanización superará el 60\%, adelantada un año, y las capitales de provincia marcarán el comienzo de la edad de oro. Sohu News, s. p. [En línea]. Recuperado de https://goo.gl/ZGrou4

Solimano, A. (coord.) (2008). Migraciones internacionales en América Latina: booms, crisis y desarrollo. Santiago: Fondo de Cultura Económica.

Wade, J. (2007). China's good earth: From urbanization to rural development under Hu Jintao's administration. Social and Cultural research. Global Asia Journal. Ocassional Paper $\mathrm{N}^{\circ} 1$.

Wallstreetcn (2019). La tasa de urbanización de la población residente en el país se acerca al 60\% Algunos nuevos objetivos de urbanización se completan antes de lo previsto. Wallstreetcn, s. p. [En línea]. Recuperado de https://goo.gl/xmTj69

Wang, F. L. (2004). Reformed migration control and new targeted people: China's hukou system in the 2000s. China Quarterly, 177, marzo, 115-132. DOI: https://doi.org/10.1017/s0305741004000074

Wang, F. L. (2005, septiembre). China's Household Registration (Hukou) System: Discrimination and Reform. Paper presented on the Congressional-executive Commission on China One Hundred Ninth Congress (Vol. 2168).

Whyte, M. K. (2012). China's post-socialist inequality. Current History, 111(746), 229234.

$\mathrm{Wu}$, J. (2005). Understanding and Interpreting Chinese Economic Reform. Zacatecas: Texere.

Wu, L. (2013). Decentralization and hukou reforms in China. Policy and Society, 32(1), $33-42$. 
Young, J. (2013). Markets, migrants and institutional change. En Autor, China's Hukou System. Londres: Palgrave Macmillan. DOI: https://doi.org/10.1057/ 9781137277312_2

Zapata-Barrero, R. (2002). L'hora dels immigrants: esferes de justícia i polítiques d'acomodació. Barcelona: Proa.

Zhang, L., y Li, M. (2016). Local fiscal capability and liberalization of urban hukou. Journal of Contemporary China, 25(102), 893-907. DOI: https://doi.org/10.1080/10670564.2016.1186362 